\title{
APPLICATION OF IMAGE ANALYSIS TO THE
}

T1-1.-2.7 IDENTIFICATION AND RATING OF ROAD

$0^{\circ}$ gembloux

faculté universitaire

des sciences agronomiques

\section{SURFACE DISTRESS}

Rasse, C.; Leemans, V.; Destain, M.-F.; Verbrugge, J.C.

RESULTS

Gembloux Agricultural University (Belgium)

Email: destain.mf@fsagx.ac.be; jverbrug@ulb.ac.be; leemans.v@fsagx.ac.be

\section{PURPOSE}

Automatic inspection of roads to detect and rate surface distress is of major interest in conditions survey and maintenance management. The objective of this research is to develop algorithms suited to detect automatically narro repairs, joints,

\section{APPROACH}

The image treatment is processed in three stages, each of them being subdivided in one or more tasks:

- the pre-treatment consists mainly in applying a background correction to eliminate the heterogeneity due to - the pre-treatment

- in the treatment, a threshold value is applied to segment the "objects" from the rest of the image; - as the objects may be cracks, part of cracks or some noise erroneously segmented as defect, a post-treatment is applied to appreciate more accurately if a pixel belonged to an object or to the background. It aims also to assembly parts of cracks in continuous structure.

Figures 1 to 4 illustrate the various stages of the process, starting with the green channel of the original image, the uniformisation of the background, the segmented image and the detected cracks.

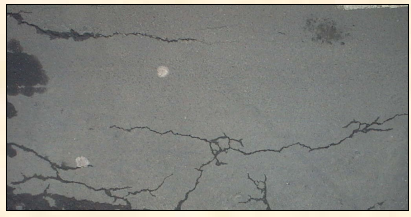

Fig. 1. Original image

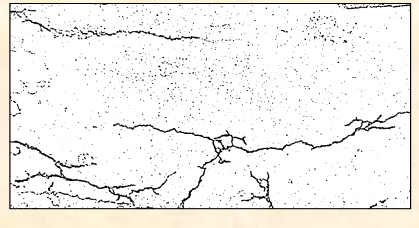

Fig. 3. Segmented image

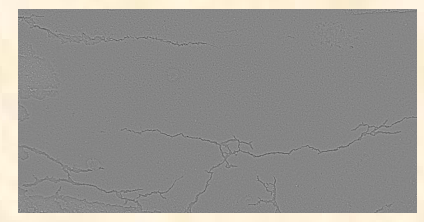

Fig. 2. Image with uniform background

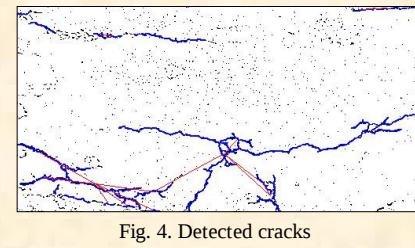

Algorithms where tested on 81 images of bituminous pavements sorted in 11 groups according to their texture, their wetness and their wear. Examples of results are given below. Comparing initial and final image, it is obvious that an efficient detection of cracks has been obtained and that parts of cracks initially considered as singular elements are assembled in conformity with visual appreciation
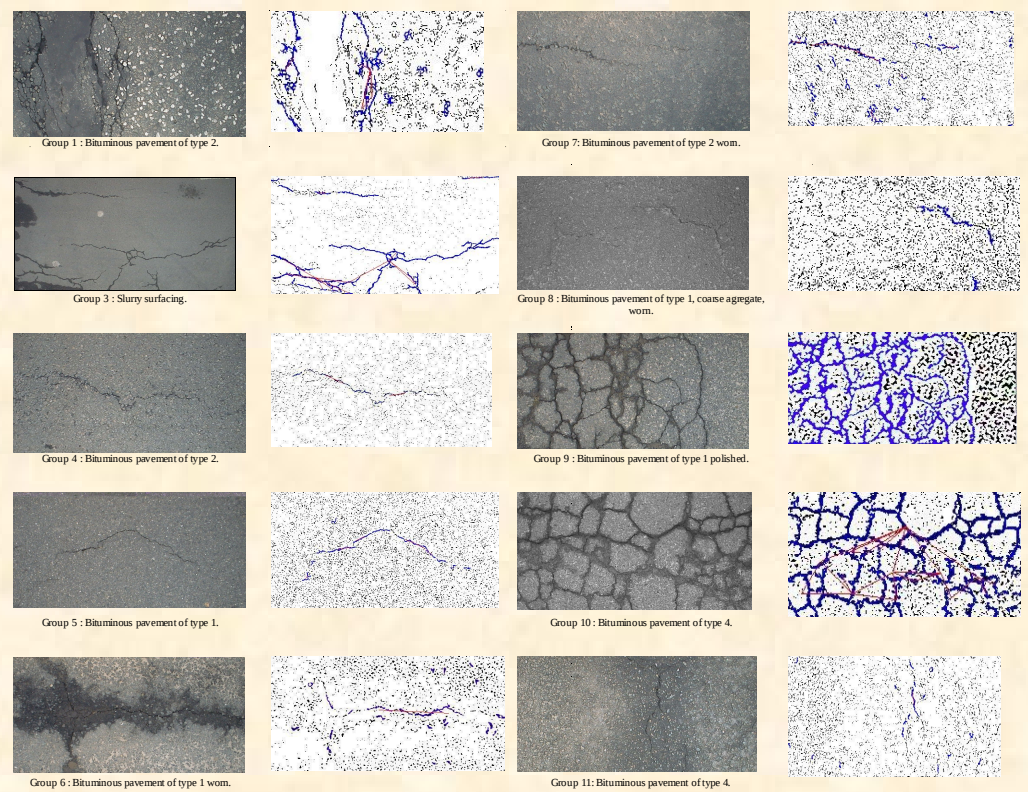

CONCLUSION

The proposed algorithms are efficient to correct the image background in order to eliminate the heterogeneity due to humidity, shade, On the treated images, they are able to detect narrow cracks on bituminous pavements. Further work is done to get an automatic detection not only of cracks, but also other distresses, whatever the road texture.

The authors would like M. Guy Lefebvre (MET - Walloon Country - Belgium) for his help in image classification.

BCRA - Lisbon 2002 